\title{
Mathematical Modeling, Investigation and comparison on the Effect of Various Alternative Fuels on the Performance of Gas Turbine Combustion Process
}

\author{
Loganathan. $V^{1}$, Vijayan. $R^{2}$, Sekar. $T^{3}$ \\ ${ }^{I}$ Department of Mechanical Engineering, Government College of Engineering-Salem, India \\ ${ }^{2}$ Department of Mechanical Engineering, Government College of Engineering-Salem, India \\ ${ }^{3}$ Department of Mechanical Engineering, Government College of Engineering-Salem, India
}

\begin{abstract}
Mathematical Models are the actual physical processes represented by a set of appropriate equations. The combustion process involved in the Gas turbine can be predicted using the Mathematical Modeling. The conservation of mass, momentum and Energy plays a vital role in the combustion process. Standard $K$-غे models are used to predict the reaction rate and turbulent viscosity. The main goal of this job it is to show the combustion models applied for an annular combustion chamber for small gas turbines, considering aspects about the speed, pressure and temperature, which can be used to feature the flame behavior and its effects in efficiency and pollution emission. The Alternative fuels have been chosen in such a way that the emission is low as well as good performance characteristics like conventional fuel. The performance parameters like Combustion Efficiency, Combustion Intensity, and Adiabatic flame Temperature and Mixture fraction has been obtained by using the Mathematical Modeling. Without carry out the experimental Work one can predict the Performance by using Mathematical Modeling. The Modeling is performed in MATLAB Simulink package and how the Performance parameters varies in relation with the changes in the variables like mass flow rate, initial temperature and Combustion pressure has been discussed and plotted in a effective way. The Results of various Alternative fuels have been compared effectively.
\end{abstract}

Keywords: Alternative Fuels,Combustion, Mathematical Model, , MATLAB Simulink, Performance Parameters

\section{Introduction}

The use of gas turbines for the regional development has been increased gradually in early years The challenges in designing high performance combustion systems have not changed significantly over the years, but the approach has shifted towards a more sophisticated analysis process. A technical discussion on combustion technology status and needs will show that the classic impediments that have hampered progress towards near stoichiometric combustion still exist. Annular combustor which offer maximum utilization of available volume, fewer requirements of cooling air and high temperature application are one class of combustor most commonly used. A well designed gas turbine combustor should have complete combustion and minimal total pressure loss over a wide range of operating conditions. Flow characteristics in the annulus passage surrounding the liner is equally important as the flow is fed into the liner through the annulus passage.

\subsection{Chemical Reaction:}

Chemical consideration is used to size the combustion chamber to allow as efficient combustion as possible. Combustion inefficiency represents waste of fuel, which is clearly unacceptable in view of the world's dwindling oil supply and escalation of fuel costs. Another important consideration is that combustion inefficiency is manifested in the form of undesirable and harmful pollutant emissions, notably unburned hydrocarbons and carbon monoxide. These implications relate the combustion efficiency with the casing area of the combustor, which in turn relates it with the liner diameter and performance of the combustion chamber.

\subsection{Need of Alternative Fuels:}

According to world energy report, around $80 \%$ of our fuel is from conventional fossil fuels. It is well known that all these sources will be completely exhausted at any time. As jet fuel constitutes only about 6 percent of global oil consumption and requires high-performance characteristics, it makes more sense to use higher performing synthetic fuels in aviation. Lastly, research and development in aviation alternate fuel needs to continue. If it is able to demonstrate additional benefits, such as exhaust pollutant and $\mathrm{CO} 2$ reduction, the fuel would become more attractive to aviation, especially in the case of carbon trading. It is essential that alternatives to crude oil be developed to help stabilize energy supplies and their associated prices and to address global warming issues. Current aircraft have experienced dramatic improvements in fuel efficiency since the 
introduction of commercial jet aircraft in the 1960s. Future aircraft will see another 15 to 20 percent improvement in fuel efficiency, making air travel one of the most efficient means of transportation. The main reasons for alternate fuel are Increase in air travelers, Fuel demand, and price hike. The demand of fuel is shown in the Figure 1 and the price hike of fuel is shown in the Figure 2.

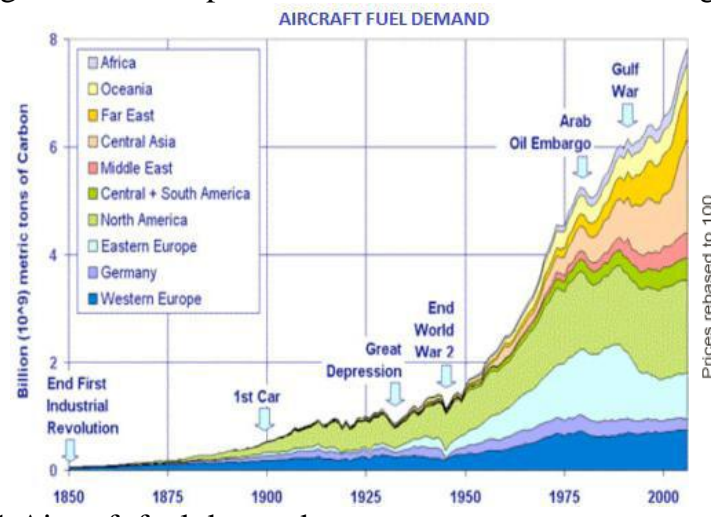

Fig 1.2.1 Aircraft fuel demand

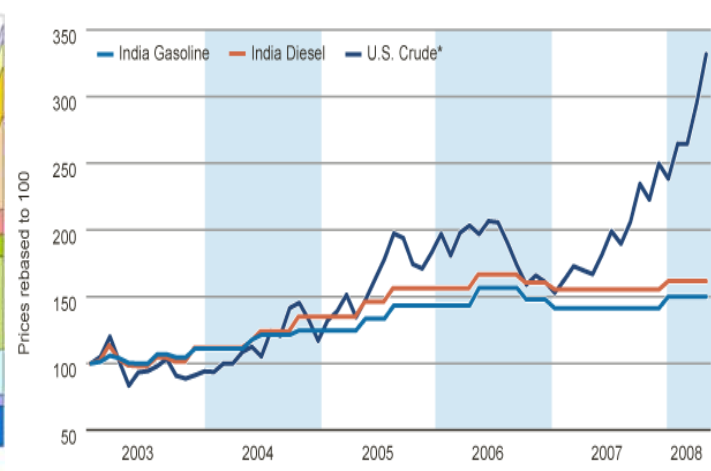

Fig 1.2.2 Price hike of fuel

\subsection{Mathematical Modeling Process:}

\section{II.Mathematical Modeling}

Mathematical modeling is the use of mathematics to describe real-world phenomena, investigate important questions about the observed world, explain real-world phenomena,test ideas and make predictions about the real world. Mathematical Models are the actual physical processes represented by a set of appropriate equations. Instead of undertaking experiments in the real world, a modeler undertakes experiments on mathematical representations of the real world.

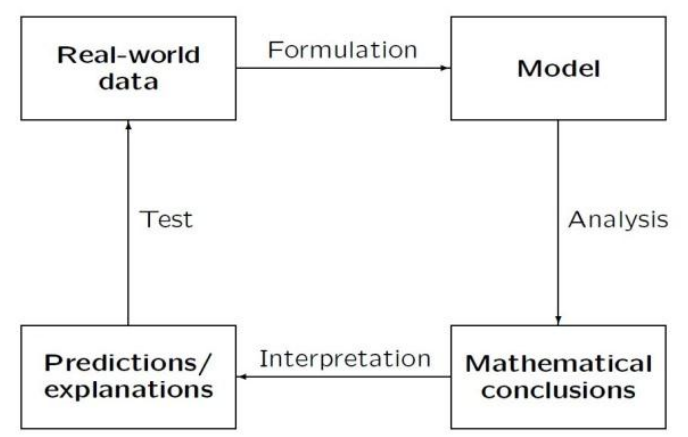

Fig 2.1.1: Mathematical Modeling Process

\section{2: Mathematical Modeling Equations:}

The governing equations of mean flow in reduced form for steady incompressible flow are,

$$
\frac{\partial}{\partial x_{i}}\left(u_{i} \rho\right)=S_{m}
$$

Mass conservation is valid for both incompressible and compressible flows. $S_{\mathrm{m}}$ is the mass added to a continuous phase from dispersed phase. Momentum Conservation equation for turbulent flow is written as,

$$
\begin{aligned}
\rho u_{j} \frac{\partial u_{i}}{\partial x_{j}} & =-\frac{\partial p}{\partial x_{i}}+\frac{\partial}{\partial x_{j}}\left[\mu\left(\frac{\partial u_{i}}{\partial x_{j}}+\frac{\partial u_{j}}{\partial x_{i}}\right)-\frac{2}{3} \mu \delta_{i j} \frac{\partial u_{i}}{\partial x_{i}}\right]+ \\
& +F_{i}+\frac{\partial}{\partial x_{j}}\left(-\overline{\rho u_{i} u_{j}^{\prime}}\right)
\end{aligned}
$$

These equations are of the same general form as the original equations for the some additional terms. The additional term are the Reynolds stresses and these need to be modeled for closure. 


$$
\overline{-\rho u_{i}^{\prime} u_{j}^{\prime}}=\mu_{t}\left(\frac{\partial u_{i}}{\partial x_{j}}+\frac{\partial u_{j}}{\partial x_{i}}\right)-\frac{2}{3}\left(\rho k+\mu_{t} \frac{\partial u_{i}}{\partial x_{i}}\right) \delta_{i j}
$$

For reacting flow energy equations need to be solved, which will give,

$$
\frac{\partial}{\partial x_{i}}\left(\rho u_{i} H\right)=\frac{\partial}{\partial x_{i}}\left(\frac{k_{b}}{c_{p}} \frac{\partial H}{\partial x_{i}}\right)+\tau_{i k} \frac{\partial u_{i}^{\prime}}{\partial x_{k}}+S_{h}
$$

The standard $k-\grave{\varepsilon}$ equations are,

$$
\begin{aligned}
& \rho u_{i} \frac{\partial k}{\partial x_{i}}=\frac{\partial}{\partial x_{i}}\left[\left(\mu+\frac{\mu_{t}}{\sigma_{k}}\right) \frac{\partial k}{\partial x_{i}}\right]+G_{k}-\rho \varepsilon+Y_{M} \\
& \rho u_{i} \frac{\partial \varepsilon}{\partial x_{i}}=\frac{\partial}{\partial x_{i}}\left[\left(\mu+\frac{\mu_{t}}{\sigma_{\varepsilon}}\right) \frac{\partial \varepsilon}{\partial x_{i}}\right]+C_{1 \varepsilon} \frac{\varepsilon}{k} G_{k}-C_{2 \varepsilon} \rho \frac{\varepsilon^{2}}{K}
\end{aligned}
$$

For turbulent flow mass diffusion species $i$ is computed as,

$$
j_{i^{\prime}, j}=-\left(\rho D_{i^{\prime}, m} \frac{\partial m_{i^{\prime}}}{\partial x_{i}}+\frac{\mu_{t}}{S c_{t}}\right) \frac{\partial m_{i^{\prime}}}{\partial x_{i}}
$$

The chemical Equations governing for the combustion process is,

$$
\mathrm{C}_{12} \mathrm{H}_{26}+18.5 \mathrm{O}_{2} \longrightarrow 12 \mathrm{CO}_{2}+13 \mathrm{H}_{2} \mathrm{O}(8)
$$

The one mole of fuel requires 18.5 moles of oxygen to produce complete combustion.

\subsection{MATLAB Simulink:}

Simulink provides a graphical editor, customizable block libraries, and solvers for modeling and simulating dynamic systems. It is integrated with MATLAB ${ }^{\circledR}$, enabling to incorporate MATLAB algorithms into models and export simulation results to MATLAB for further analysis. Simulink, developed by Math Works, is a data flow graphical programming language tool for modeling, simulating and analyzing multi domain dynamic systems. Its primary interface is a graphical block diagramming tool and a customizable set of block libraries. It offers tight integration with the rest of the MATLAB environment and can either drive MATLAB or be scripted from it.Performance predictions can be obtained for the combustion process in MATLAB Simulink and the result has been obtained graphically.

\section{III.Performance Of Combustion Systems (Matlab Simulink)}

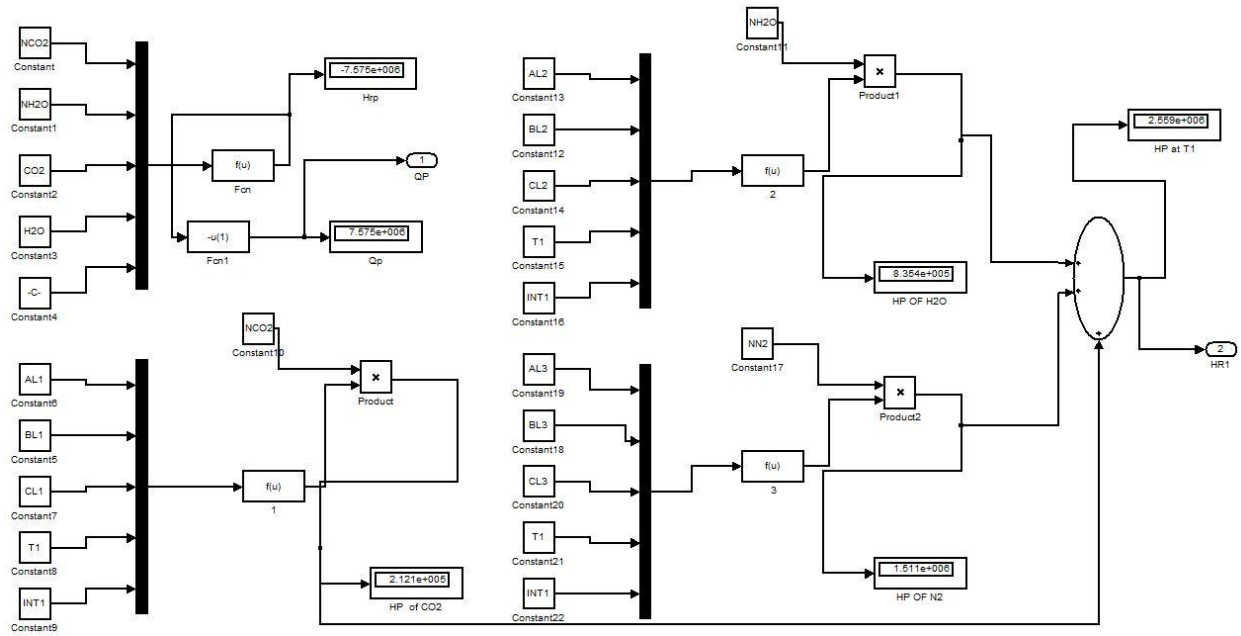

Fig 3.1: Mathematical modeling for heat of Reaction in Combustion process 


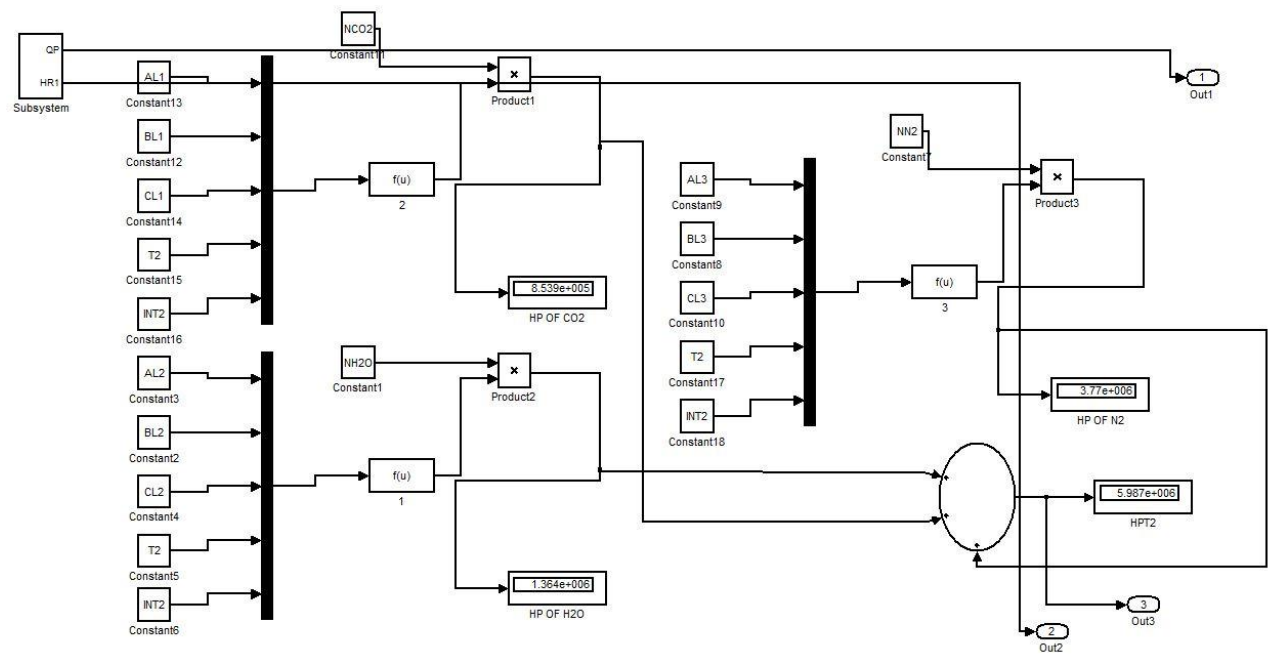

Fig 3.2 : Mathematical Modeling of Enthalpy of the Combustion products

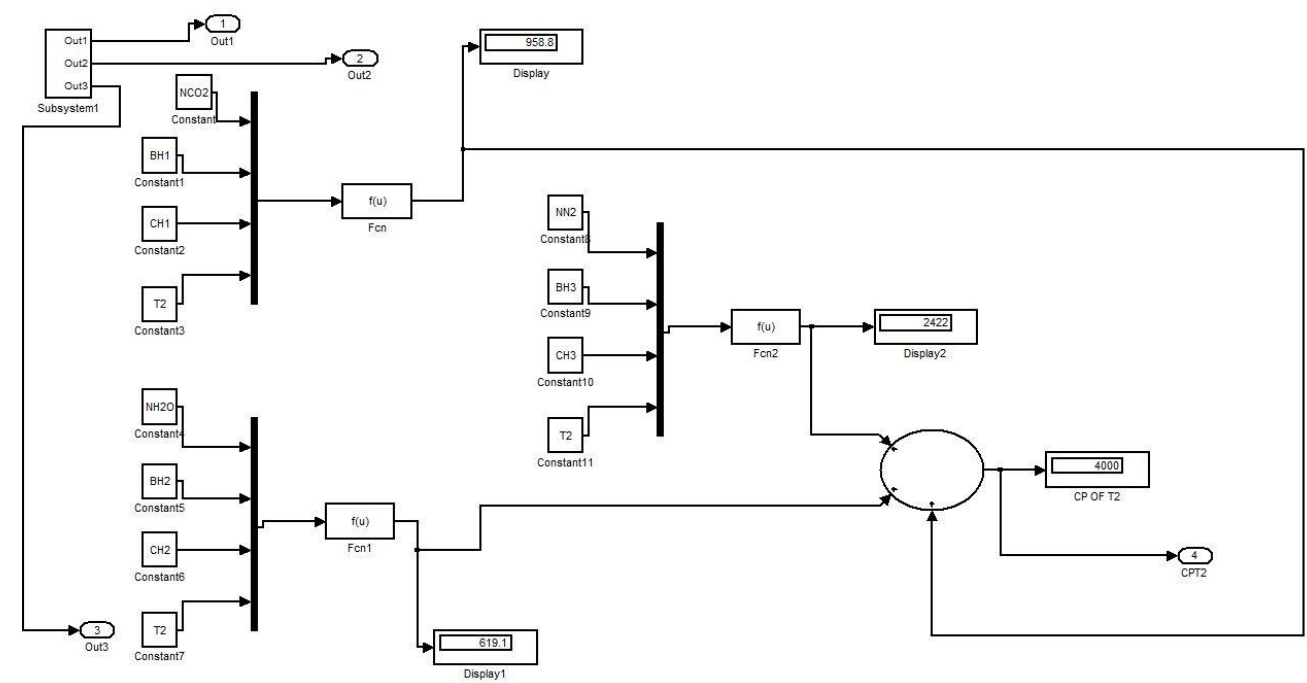

Fig 3.3 : Mathematical Modeling of Specific heat of the Combustion Products
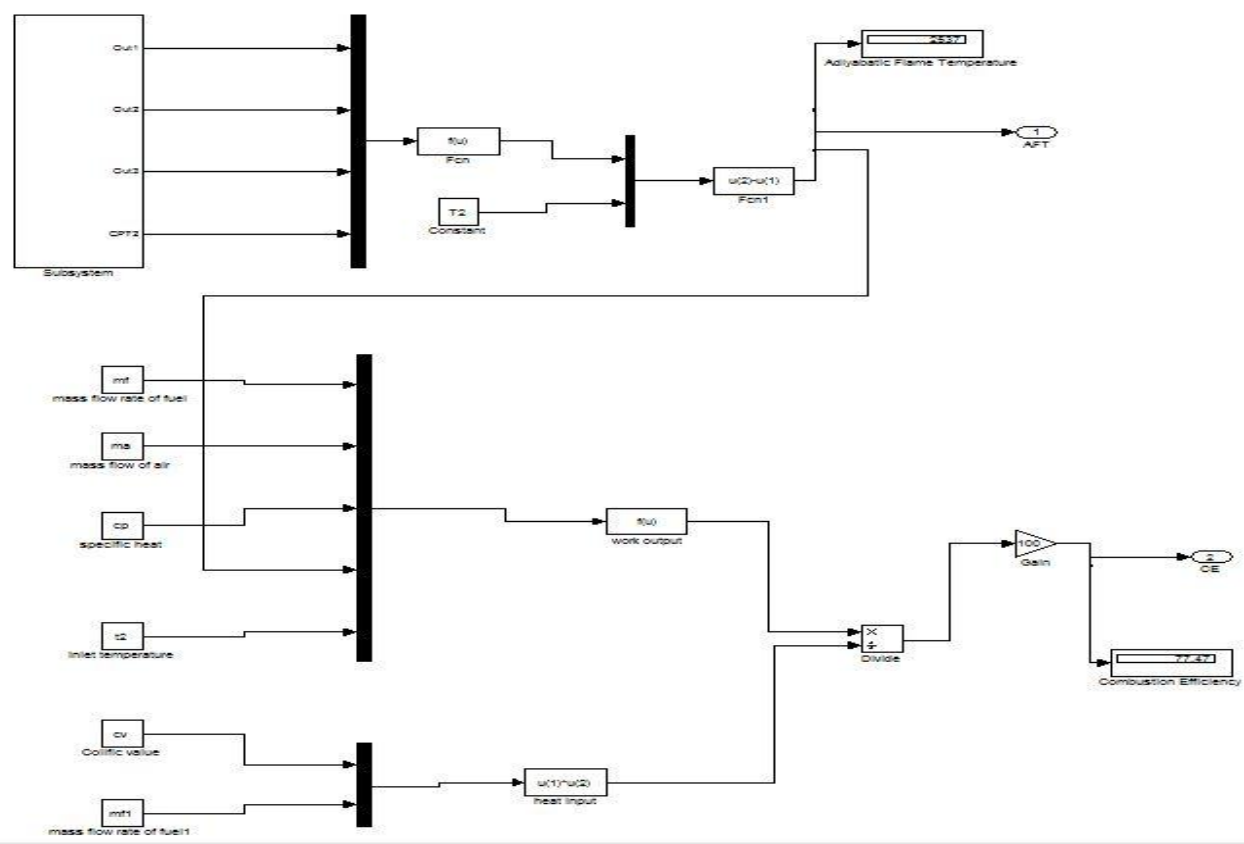

Fig 3.4 : mathematical Modeling for Combustion Efficiency and Adiabatic Flame Temperature 


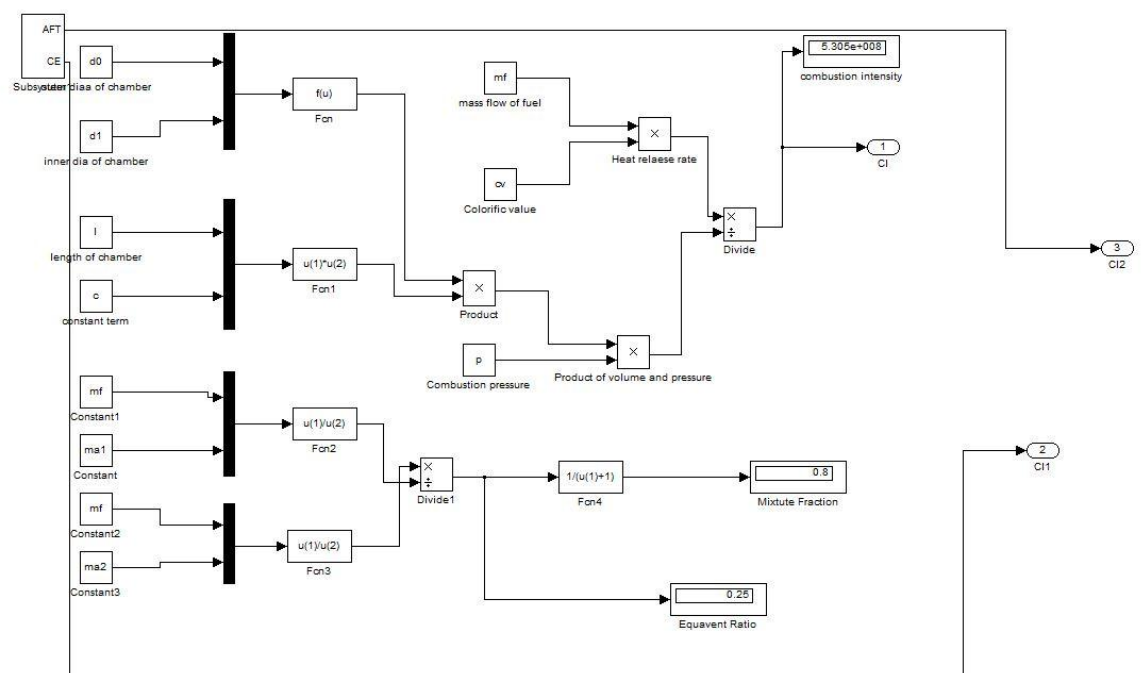

Fig 3.5 : Mathematical Modeling for Combustion Intensity and mixture fracture

In Fig 3.1 The mathematical Modeling of the heat of reaction which is neeeded to produce complete combustion as well as the good performance considerations.In Fig 3.2 The mathematical Modeling is done to predict the Enthalpy of the combustion Products at initial and guessed temperature range.In Fig 3.3 The mathematical Modeling has been carried out to ensure the specific heat of the combustion product within the range of operation of the combustion process.In Fig 3.4 The Mathematical Modeling has been carried out for the combustion Efficiency and the Adiabatic Flame Temperature. Adiabatic Flame Temperature plays a vital Role in the Performance of Gas Turbine Combustion Chamber.In Fig 3.5 The Mathematical Modeling is done to predict the performance characters like combustion intensity and the mixture fraction has been carried out.

\section{IV.Performance Analysis Of Combustion Process (Alternative Fuels):}

Table 4. 1: Effect of Combustion Inlet Temp on ATF for Various Alternate Fuels

\begin{tabular}{|c|c|c|c|c|}
\hline S.NO & $\begin{array}{c}\text { Combustion initial } \\
\text { Temperature(K) }\end{array}$ & $\begin{array}{c}\text { Aviation kerosene+ } \\
\text { Methane } \\
\text { (AFT in K) }\end{array}$ & $\begin{array}{c}\text { Aviation Kerosene } \\
\text { +Propane } \\
\text { (AFT in K) }\end{array}$ & $\begin{array}{c}\text { Methane +Propane } \\
\text { (AFT in K) }\end{array}$ \\
\hline 1 & 400 & 2423 & 2437 & 2482 \\
\hline 2 & 420 & 2436 & 2451 & 2496 \\
\hline 3 & 440 & 2450 & 2464 & 2510 \\
\hline 4 & 460 & 2464 & 2478 & 2524 \\
\hline 5 & 480 & 2478 & 2493 & 2538 \\
\hline 6 & 500 & 2493 & 2507 & 2568 \\
\hline 7 & 520 & 2508 & 2522 & 2583 \\
\hline 8 & 540 & 2523 & 2537 & 2598 \\
\hline 9 & 560 & 2538 & 2552 & 2613 \\
\hline 10 & 580 & 2553 & 2567 & \\
\hline
\end{tabular}

From Table 4.1 it is clear that how the variation of combustion initial temperature affects the adiabatic flame temperature for various alternative fuels.

Table 4.2: Effect of Combustion inlet temp on Combustion Efficiency for various Alternate Fuels

\begin{tabular}{|c|c|c|c|c|}
\hline S.NO & $\begin{array}{c}\text { Combustion initial } \\
\text { Temperature(K }\end{array}$ & $\begin{array}{c}\text { Aviation kerosene+ } \\
\text { Methane } \\
\text { (Combustion efficiency in } \\
\text { \%) }\end{array}$ & $\begin{array}{c}\text { Aviation kerosene+ } \\
\text { Propane } \\
\text { (Combustion efficiency in } \\
\text { \%) }\end{array}$ & $\begin{array}{c}\text { Propane+ Methane } \\
\text { (Combustion efficiency in } \\
\text { \%) }\end{array}$ \\
\hline 1 & 400 & 78.27 & 74.21 & 74.94 \\
\hline 2 & 420 & 78.01 & 73.97 & 74.71 \\
\hline 3 & 440 & 77.78 & 73.75 & 74.48 \\
\hline 4 & 460 & 77.54 & 73.53 & 74.07 \\
\hline 5 & 480 & 77.32 & 73.32 & 73.87 \\
\hline 6 & 500 & 77.11 & 73.12 & 73.69 \\
\hline 7 & 520 & 76.91 & 72.93 & 73.34 \\
\hline 9 & 540 & 76.71 & 72.75 & 73.17 \\
\hline 10 & 560 & 76.53 & 72.57 & 72.4 \\
\hline
\end{tabular}


From Table 4.2 it is cleared that the how the combustion inlet temperature affects the performance of "combustion efficiency".

Table 4. 3: Effect of Combustion Pressure on Combustion Intensity for various Alternate Fuel

\begin{tabular}{|c|c|c|c|c|}
\hline S.NO & $\begin{array}{c}\text { Combustion } \\
\text { pressure(bar) }\end{array}$ & $\begin{array}{c}\text { Aviation kerosene+ } \\
\text { Methane } \\
\text { (Combustion intensity in } \\
\text { W/m } / \mathbf{m}^{3} \text { atm) }\end{array}$ & $\begin{array}{c}\text { Aviation kerosene+ } \\
\text { Methane } \\
\text { (Combustion intensity in } \\
\text { W/m } / \mathbf{m}^{3} \text { atm) }\end{array}$ & $\begin{array}{c}\text { Aviation kerosene+ } \\
\text { Methane } \\
\text { (Combustion intensity in } \\
\text { W/m } \mathbf{m}^{3} \text { atm) }\end{array}$ \\
\hline 1 & 7 & 8.047 & 7.914 & 8.411 \\
\hline 2 & 8 & 7.041 & 6.925 & 7.360 \\
\hline 3 & 9 & 6.258 & 6.155 & 6.542 \\
\hline 4 & 10 & 5.633 & 5.54 & 5.888 \\
\hline 5 & 11 & 5.121 & 5.036 & 5.353 \\
\hline 6 & 12 & 4.694 & 4.616 & 4.907 \\
\hline 7 & 13 & 4.333 & 4.261 & 4.529 \\
\hline 8 & 14 & 4.023 & 3.957 & 4.206 \\
\hline 9 & 15 & 3.755 & 3.925 & 3.925 \\
\hline 10 & 16 & 3.52 & 3.68 & 3.68 \\
\hline
\end{tabular}

In Table 4.3 shows that, whenever the combustion pressure varies automatically the combustion intensity changes accordingly.

Table 4. 4: Effect of mass flow rate on Combustion intensity for various Alternate fuels

\begin{tabular}{|c|c|c|c|c|}
\hline S.NO & Mass Flow rate(kg/s) & $\begin{array}{c}\text { Aviation kerosene+ } \\
\text { Methane } \\
\text { (Combustion intensity in } \\
\text { W/m } \mathbf{m}^{3} \text { atm) }\end{array}$ & 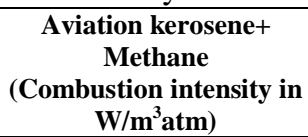 & $\begin{array}{c}\text { Aviation kerosene+ } \\
\text { Methane } \\
\text { (Combustion intensity in } \\
\text { W/m } \mathbf{m}^{3} \text { atm) }\end{array}$ \\
\hline 1 & 1.2 & 6.759 & 6.648 & 7.066 \\
\hline 2 & 1.4 & 7.886 & 7.755 & 8.243 \\
\hline 3 & 1.6 & 9.012 & 8.863 & 9.421 \\
\hline 4 & 1.8 & 10.14 & 9.971 & 10.60 \\
\hline 5 & 2 & 11.27 & 11.08 & 11.78 \\
\hline 6 & 2.2 & 12.39 & 12.19 & 12.95 \\
\hline 7 & 2.4 & 13.52 & 13.31 & 14.13 \\
\hline 8 & 2.6 & 14.64 & 14.4 & 15.31 \\
\hline 9 & 2.8 & 15.77 & 15.5 & 16.49 \\
\hline 10 & 3 & 16.90 & 16.62 & 17.66 \\
\hline
\end{tabular}

From Table 4.4 it is cleared that the variation of combustion intensity in relation with mass flow rate of the fuel and air.

V. Results And Discussions

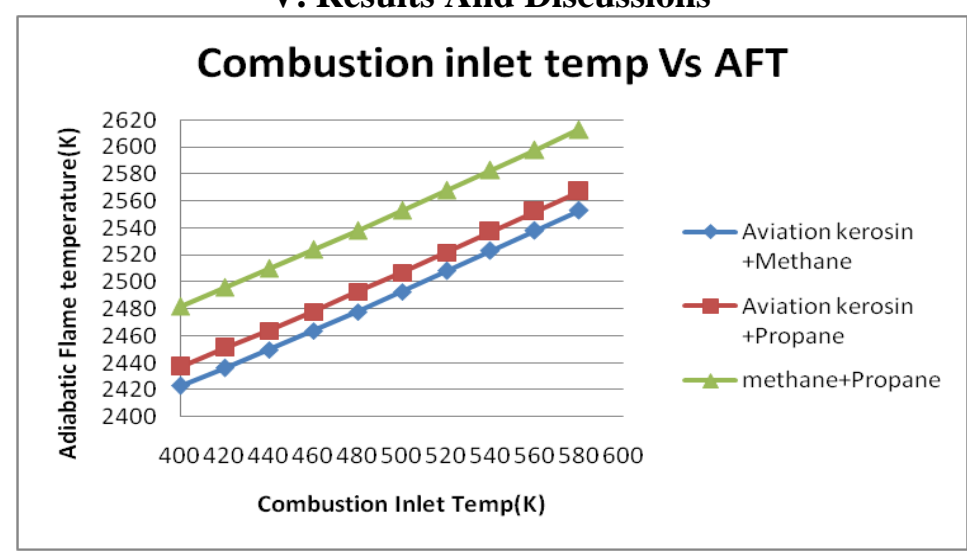

Fig 5.1 Combustion inlet Temperature Vs Adiabatic Flame Temperature

Fig 5.1 shows the variation of Adiabatic Flame temperature in accordance with the combustion inlet temperature. From the fig it is cleared that the adiabatic flame temperature varies linearly with combustion inlet temperature.

From fig 5.2 it is predicted that whenever the combustion inlet temperature increases there is slightly reduction in the combustion efficiency.

In Fig 5.3 it is well known that the variation of combustion intensity in relevance to the combustion pressure decreases parabolically. 


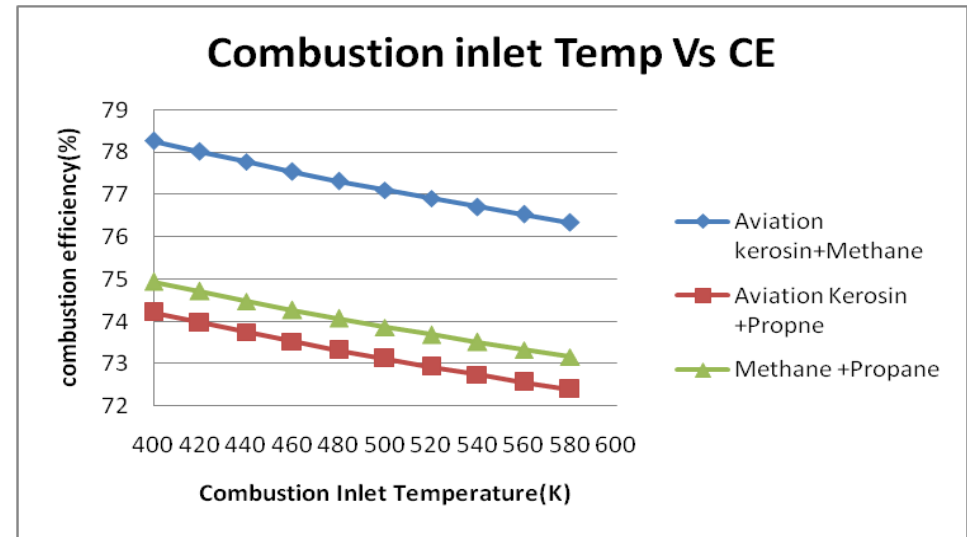

Fig 5.2 Combustion inlet Temperature Vs Combustion Efficiency

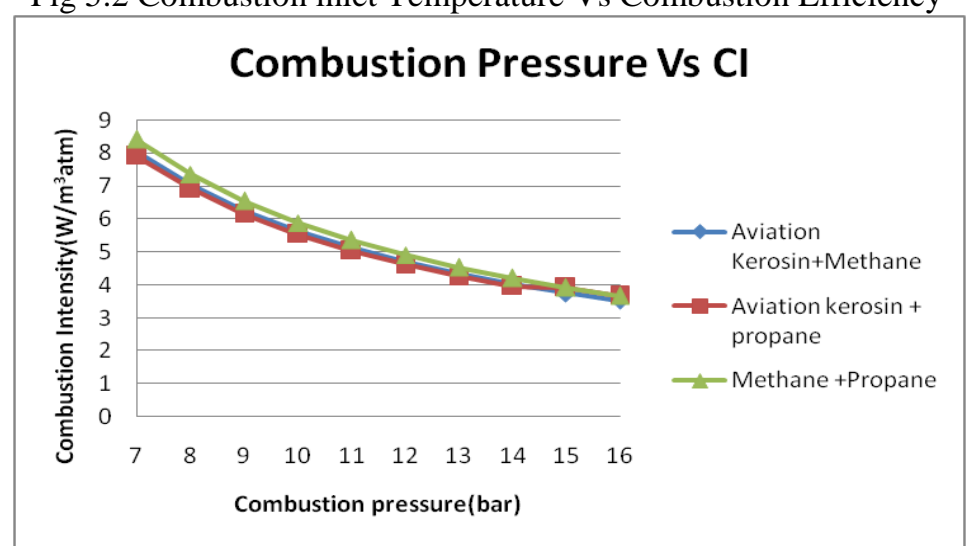

Fig 5.3 Combustion pressure Vs Combustion Intensity

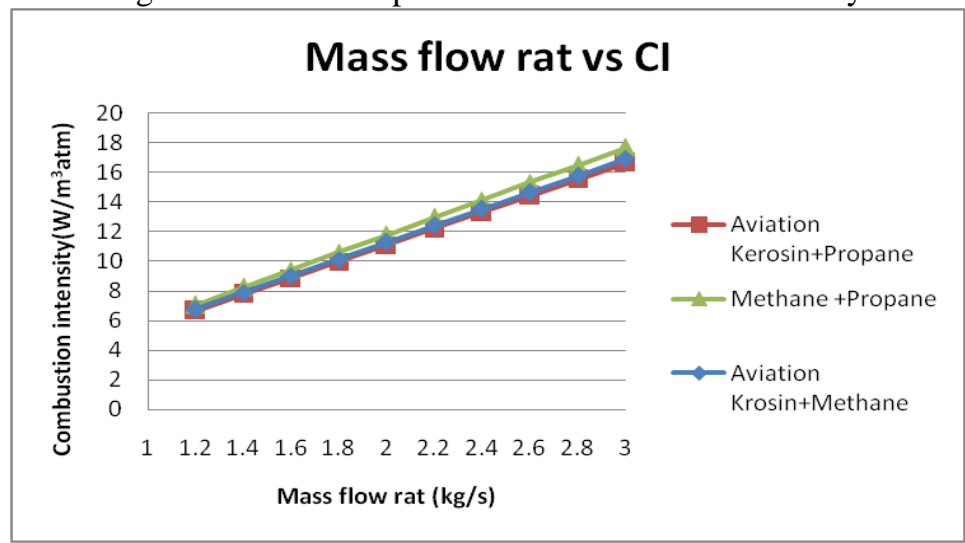

Fig 5.4 Mass flow rate Vs Combustion Intensity

From Fig 5.4 it is clear that the increases in the mass flow rate leads to an increases in the combustion intensity

\section{VI.Conclusion}

The Performance of gas Turbine Combustion process has been obtained using Mathematical modeling. The real world phenomena of the combustion in gas turbine engines carried out effectively with the aid of various mathematical modeling Technique. The Modeling has been obtained for annular combustion Chamber which provides minimum pressure loss in the combustion chamber. The Modeling has been carried out in MATLAB Simulink package. The Effect of Combustion inlet temperature on the Adiabatic Flame Temperature as well as Combustion Efficiency, The effect of Combustion pressure and mass flow rate on the Combustion intensity has been obtained using mathematical modeling. The performance parameters are determined and the performance graphs are plotted effectively. The mathematical modeling is a tool to predict the performance of a gas turbine engine without any experimental setup and experimental data. Gas Turbine Engine is very costly, to carry out an experimental it takes lot of money and which is practically tedious process. The mathematical modeling is a powerful tool which can be widely used in many other complex situations of real world phenomena. 


\section{References}

[1] Harley Souza, AlencarHelcio, Francisco Villanova, Marco Antonio Rosa, Modeling of an annular Combustion chambers using CFDProceedings of the 3rd IASME/WSEAS Int. Conf. on Hat Transfer, Thermal Engineering and Environment , Corfu, Greece, August 20-22, 2005 (pp317-325).

[2] . K. V. Chaudhari, D. B. Kulshreshtha, and S.A. Channiwala, Design and CFD Simulation of Annular combustion chamber with Kerosene as a fuel for 20KW Gas turbine Engine, International Journal of Engineering Research and Applications (IJERA) ISSN: 2248-9622 Vol. 2, Issue 6, November-December 2012, pp.1641-1645

[3] K. Sreenivasarao, S.K. Bhatti,CFD Modeling of an Aero Gas Turbine Combustor for a small scale Gas turbine Engine ,International Journal of Engineering Research \& Technology (IJERT) Vol. 2 Issue 1, January- 2013.

[4] Richard guiler, Emissions and Operational Aspects of Methanol as an Alternative Fuel in a Stationary gas turbine Engine, PhD thesis submitted at West Virginia University in 2000

[5] Sara Eriksson,Development of Catalysts for Natural gas Fired gas Turbine Combustors, PhD Thesis submitted at royal Institute of Technology, Sweden in 2006

[6] Cheng Tung Chong, Combustion Characteristics of Alternative Liquid Fuels,PhD Thesis submitted in 2011.

[7] Miguel correiaGraca, Computational Investigation of a Reversed Flow Small Scale Combustor, PhD thesis submitted in 2011. 